\title{
Bone Morphogenetic Protein 2 and Transforming Growth Factor $\beta 1$ Inhibit the Expression of the Proinflammatory Cytokine IL-34 in Rheumatoid Arthritis Synovial Fibroblasts
}

\author{
Marguerite Chemel, ${ }^{* \dagger+}$ Regis Brion, ${ }^{* \dagger}$ Aude-Isabelle Segaliny, ${ }^{* \dagger}$ Audrey Lamora, ${ }^{* \dagger}$ Celine Charrier, ${ }^{* \dagger}$ \\ Benedicte Brulin, ${ }^{* \dagger}$ Yves Maugars, ${ }^{\star}$ Benoit Le Goff, ${ }^{* \dagger}$ Dominique Heymann, ${ }^{* \dagger \ddagger \S}$ and Franck Verrecchia ${ }^{* \dagger}$
}

\begin{abstract}
From the French National Cancer League Team 2012,* INSERM, UMR 957, Nantes, France; the Pathophysiology of Bone Resorption and Primary Bone Tumors Laboratory, ${ }^{\dagger}$ Université de Nantes, Nantes, France; the Musculoskeletal Department, ${ }^{\ddagger}$ Nantes University Hospital, Nantes, France; and the Department of Oncology and Metabolism, ${ }^{\S}$ INSERM European Associated Laboratory, Sarcoma Research Unit, The Medical School, University of Sheffield, Sheffield, United Kingdom
\end{abstract}

Accepted for publication September 8, 2016.

Address correspondence to Dominique Heymann, Ph.D., or Franck Verrecchia, Ph.D., INSERM UMR957, Faculté de Médecine, 1 rue Gaston Veil, 44000 Nantes, France. E-mail: dominique.heymann@univnantes.fr or franck.verrecchia@ inserm.fr.

\begin{abstract}
IL-34 is a proinflammatory cytokine implicated in rheumatoid arthritis (RA). The current study aimed to assess the IL-34 expression in response to two members of the transforming growth factor (TGF)- $\beta$ family, TGF- $\beta 1$ and bone morphogenetic protein (BMP)-2, in synovial fibroblasts from RA patients. IL-34, TGF- $\beta 1$, and BMP-2 productions were measured in patient synovial fluids by enzyme-linked immunosorbent assay. IL-34 mRNA levels were quantified by real-time quantitative PCR in human synovial fibroblasts and murine mesenchymal stem cells. Pharmacologic inhibitions were used to determine the involvement of activin receptor-like kinase 1 (ALK1) and ALK5 downstream TGF- $\beta 1$ and BMP-2. IL-34, TGF- $\beta 1$, and BMP-2 were expressed in synovial fluids from RA patients. We found a significant correlation between IL-34 and TGF- $\beta 1$ expressions. Levels of both IL-34 and TGF- $\beta 1$ were thus correlated with the total leukocyte counts in the synovial fluids. TGF- $\beta 1$ and BMP-2 decreased IL-34 expression in the synovial fibroblasts or in murine mesenchymal stem cells in a dose- and timedependent manner through ALK5 and ALK1 pathways, respectively. In addition, TGF- $\beta 1$ and BMP-2 antagonized tumor necrosis factor $\alpha$-induced IL-34 gene expression. This work identifies TGF- $\beta 1$ and BMP-2 as potent inhibitors of IL-34 expression in RA synovial fibroblasts. These cytokines, as upstream inhibitors of IL-34, may thus contribute to antagonize inflammation and bone erosions in RA. (Am J Pathol 2017, 187: 156-162; http://dx.doi.org/10.1016/j.ajpath.2016.09.015)
\end{abstract}

Rheumatoid arthritis (RA) is an autoimmune disease characterized by a chronic inflammation of the synovial tissue that leads to progressive joint destruction. ${ }^{1}$ Among the cells located in the inflamed joint, synovial fibroblasts are crucial players driving inflammation and bone erosion. $^{2}$

IL-34, ${ }^{3}$ basically described as promoting monocyte proliferation and survival and osteoclast differentiation, ${ }^{4}$ is expressed by synovial fibroblasts of RA patients. Its expression, correlated with inflammation, the number of leukocytes, and the severity of the synovitis are up-regulated by tumor necrosis factor $\alpha(\mathrm{TNF} \alpha)$ and IL-1 $\beta$.
Transforming growth factor (TGF)- $\beta$ s and bone morphogenetic proteins (BMPs), are proteins involved in control of many biological processes such as cell proliferation and differentiation. The importance of TGF- $\beta$ for the pathogenesis of arthritis is emphasized by several observations made in patients and in animal models. TGF- $\beta 1$ and its receptor T $\beta$ RII were detected at high levels in the synovial fibroblasts of RA patients and in RA

\footnotetext{
Supported by a Ph.D. fellowship from the Region des Pays de la Loire (CIMATH II Research Program) (A.-I.S.).

Disclosures: None declared.
} 
Table 1 Characteristics of Patients Included in the Study

\begin{tabular}{|c|c|c|c|c|c|c|c|c|}
\hline \multirow{2}{*}{$\begin{array}{l}\text { Leukocyte } \\
\text { number } / \mathrm{mm}^{3}\end{array}$} & \multirow[b]{2}{*}{ DMARS/biotherapy } & \multirow[b]{2}{*}{ Corticosteroids } & \multirow[b]{2}{*}{ Sex } & \multirow{2}{*}{$\begin{array}{l}\text { Age, } \\
\text { years }\end{array}$} & \multirow{2}{*}{$\begin{array}{l}\text { Duration of } \\
\text { disease, months }\end{array}$} & \multicolumn{2}{|c|}{ Antibody status } & \multirow[b]{2}{*}{$\mathrm{CRP}, \mathrm{mg} / \mathrm{L}$} \\
\hline & & & & & & ACPA & $\mathrm{RF}$ & \\
\hline \multicolumn{9}{|c|}{ High inflammatory fluids } \\
\hline 22,500 & Tocilizumab & + & M & 59 & 408 & - & + & 45 \\
\hline 21,000 & Tocilizumab/MTX & + & M & 65 & 3 & + & + & 217 \\
\hline 33,600 & Tocilizumab & - & M & 53 & 132 & + & + & $<5$ \\
\hline 44,100 & MTX & + & M & 40 & 10 & - & + & 109 \\
\hline 48,000 & & + & $\mathrm{F}$ & 71 & 456 & - & NM & NM \\
\hline 43,080 & & - & $\mathrm{F}$ & 74 & 84 & - & - & NM \\
\hline 39,900 & & - & M & 77 & 36 & + & + & 64 \\
\hline 38,300 & & - & $\mathrm{F}$ & 74 & 72 & - & - & 23 \\
\hline 10,710 & Tocilizumab & + & $\mathrm{F}$ & 66 & 216 & + & + & 30 \\
\hline 19,920 & Rituximab & + & $\mathrm{F}$ & 55 & 228 & - & + & NM \\
\hline 17,000 & Adalimumab/MTX & + & $M$ & 53 & 144 & NM & + & 62 \\
\hline 13,000 & MTX & + & $\mathrm{F}$ & 66 & NM & NM & NM & NM \\
\hline 11,600 & MTX/hydroxychloroquine & + & $\mathrm{F}$ & 64 & 1 & + & $=$ & 47 \\
\hline \multicolumn{9}{|c|}{ Low inflammatory fluids } \\
\hline 2280 & Abatacept/MTX & + & $\mathrm{F}$ & 72 & $>200$ & + & + & 6 \\
\hline 9120 & Tocilizumab & + & $\mathrm{F}$ & 66 & 48 & - & - & 31 \\
\hline NM & Tocilizumab/MTX & + & $\mathrm{F}$ & 61 & 240 & + & + & NM \\
\hline 5600 & Tocilizumab & + & $\mathrm{F}$ & 44 & 108 & - & + & 104 \\
\hline 2070 & Adalimumab/MTX & - & $\mathrm{F}$ & 43 & 192 & + & - & 10 \\
\hline 7440 & MTX & + & $\mathrm{F}$ & 52 & 20 & + & - & NM \\
\hline 7420 & MTX & + & $\mathrm{F}$ & 83 & 36 & + & + & 24.7 \\
\hline 4500 & MTX & + & $\mathrm{F}$ & 37 & NM & - & - & NM \\
\hline 3500 & MTX & + & $F$ & 76 & NM & NM & + & NM \\
\hline 9000 & & + & $\mathrm{F}$ & 48 & 144 & + & + & NM \\
\hline 1200 & & - & $\mathrm{F}$ & 68 & 140 & - & - & 29.8 \\
\hline 4800 & & + & $\mathrm{F}$ & 73 & 9 & + & + & 30 \\
\hline 1380 & & + & $\mathrm{F}$ & 45 & 120 & + & + & 182 \\
\hline 2640 & & + & $\mathrm{F}$ & 45 & 120 & + & + & 182 \\
\hline 1500 & NM & NM & $\mathrm{F}$ & 55 & NM & NM & NM & NM \\
\hline 4590 & & - & $M$ & 71 & 4 & - & - & 87.7 \\
\hline 9120 & & - & $M$ & 46 & 1 & + & + & 35 \\
\hline NM & NM & NM & $\mathrm{F}$ & 59 & NM & NM & NM & NM \\
\hline
\end{tabular}

F, female; M, male; +, positive; -, negative; ACPA, anti-citrullinated protein antibody; CRP, C-reactive protein; DMARS, disease-modifying antirheumatic drugs; MTX, methotrexate; NM, not measured; RF, rheumatoid factor.

synovial fluids. ${ }^{7-9}$ In this context, numerous studies have demonstrated the beneficial effects of TGF- $\beta$ in RA. ${ }^{6}$ TGF- $\beta 1$ suppresses acute and chronic arthritis in experimental models, and a strong increase of TGF- $\beta 1$ expression was measured in the remission state of disease. ${ }^{10}$ Much less data exist regarding the role of BMP during the pathogenesis of RA. However, increasing evidences suggest that BMPs, known to play a crucial role in skeletal development, could play a major role in RA to restore function of synovial joints. ${ }^{11}$ In this study, we hypothesized that IL-34 expression could be modulated by TGF- $\beta 1$ and BMP-2. 
Table 2 Sequences of Primers

\begin{tabular}{|c|c|}
\hline Primer & Sequence \\
\hline $\begin{array}{l}\text { Human IL34 } \\
\text { sense }\end{array}$ & 5'-CTTACGAGGGGGTGTTCAGA-3' \\
\hline $\begin{array}{c}\text { Human IL34 } \\
\text { antisense }\end{array}$ & 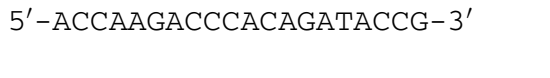 \\
\hline $\begin{array}{l}\text { Mouse IL34 } \\
\text { sense }\end{array}$ & 5'-GGACACACTTCTGGGGACA-3' \\
\hline $\begin{array}{r}\text { Mouse IL34 } \\
\text { antisense }\end{array}$ & $5^{\prime}$-CCAAAGCCACGTCAAGTAGG- $3^{\prime}$ \\
\hline $\begin{array}{l}\text { Human GAPDH } \\
\text { sense }\end{array}$ & 5'-TGGGTGTGAACCATGAGAAGTATG-3' \\
\hline $\begin{array}{l}\text { Human GAPDH } \\
\text { antisense }\end{array}$ & 5'-GGTGCAGGAGGCATTGCT-3' \\
\hline $\begin{array}{l}\text { Mouse Hprt } \\
\text { sense }\end{array}$ & 5'-TCCTCCTCAGACCGCTTTT-3' \\
\hline $\begin{array}{r}\text { Mouse Hprt } \\
\text { antisense }\end{array}$ & 5'-CCTGGTTCATCATCGCTAATC-3' \\
\hline
\end{tabular}

\section{Materials and Methods}

\section{Synovial Fluid}

Synovial fluids were obtained in the Rheumatologist Unit of Nantes University Hospital. The clinical characteristics of patients are summarized in Table 1 . The study was approved by the local ethic committee and by the French Research Ministry (no. 2008-402). IL-34, BMP-2, and TGF- $\beta$ levels were measured in synovial fluids by enzyme-linked immunosorbent assay [antibodies-online-GmbH (Aachen, Germany) for IL-34; R\&D Systems (Minneapolis, MN) for BMP-2 and TGF- $\beta 1]$.

\section{Cell Cultures}

Synovial fibroblasts, obtained from the synovial tissue of RA patients, and murine C3H10T1/2 mesenchymal stem cells (mMSCs), purchased from ATCC (CCL-226; Manassas, VA), were cultured in $\alpha$-minimal essential medium (Invitrogen, Carlsbad, CA) supplemented with $10 \%$ fetal bovine serum (Hyclone Perbio, Logan, UT). TGF- $\beta 1$ and BMP-2 were purchased from R\&D Systems. ALK1 inhibitor (LDN 212854) and ALK5 inhibitor (SB431542) were purchased from Sigma-Aldrich (St. Louis, MO).

\section{RT-PCR Analysis}

RNA was extracted using the NucleoSpin RNAII kit (Macherey-Nagel, Hoerdt, France). One microgram of total
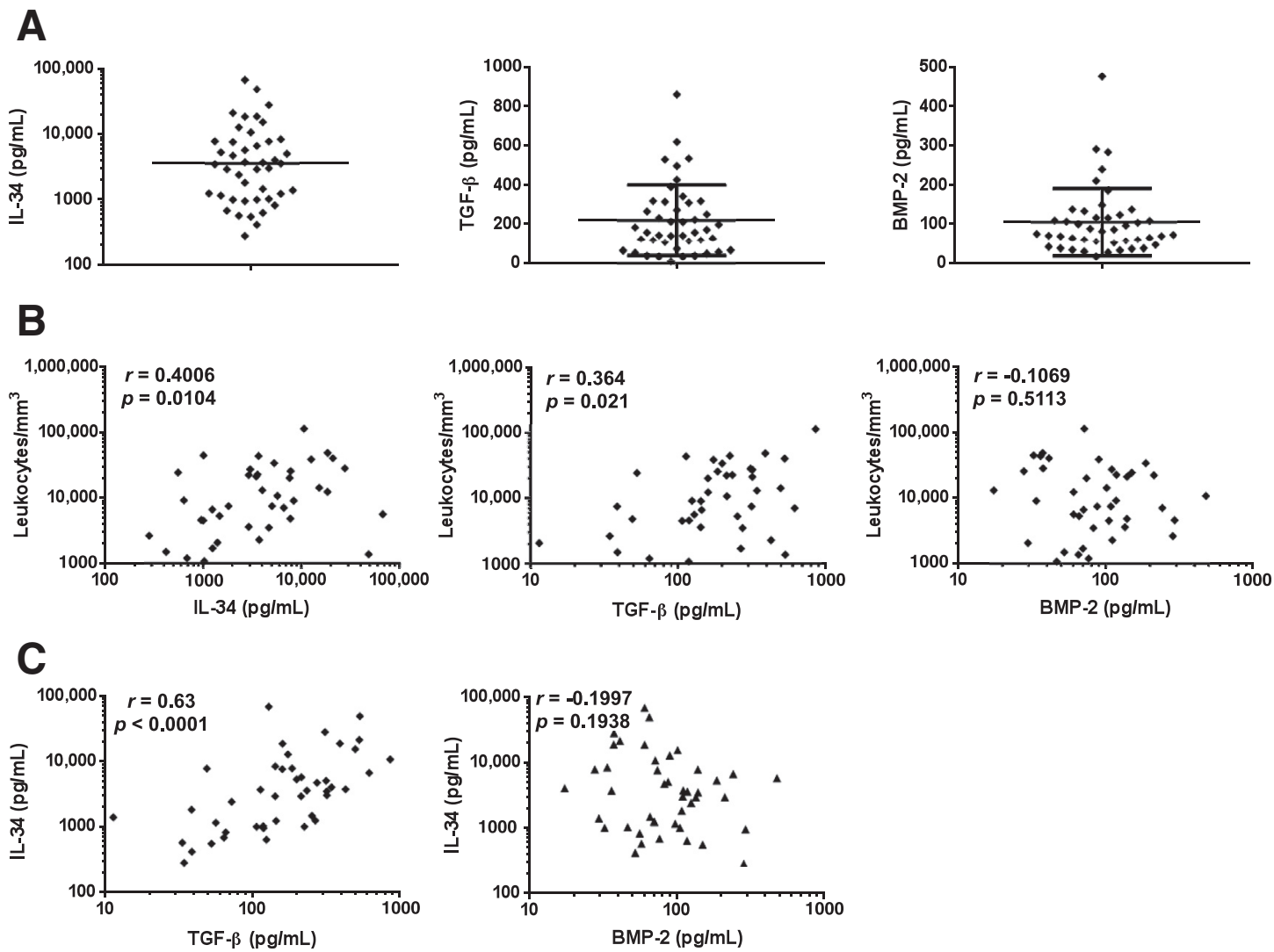

Figure 1 IL-34, TGF- $\beta 1$, and BMP-2 production in synovial fluid. Synovial fluid samples of RA patients were collected. A: Detection of IL-34, TGF- $\beta 1$, and BMP-2 in synovial fluids. B: Correlation between levels of IL-34, TGF- $\beta 1$, BMP-2, and total leukocytes. C: Correlation between levels of IL-34 and TGF- $\beta$ and of IL-34 and BMP-2. Data are expressed as means \pm SD (B). Each plot represents an individual sample. $n=44$ RA patients. BMP, bone morphogenetic protein; RA, rheumatoid arthritis; TGF, transforming growth factor. 
A

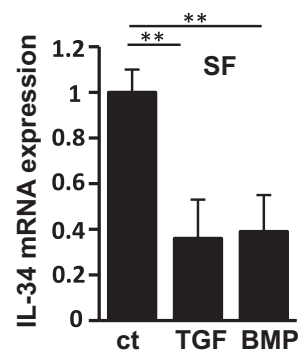

B

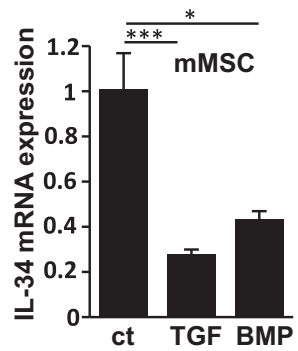

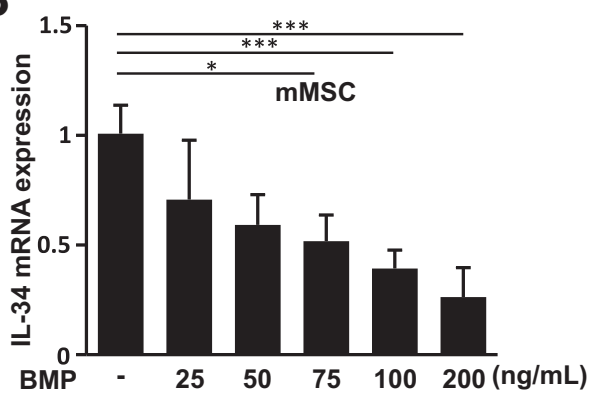

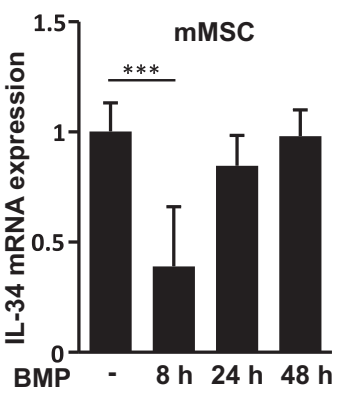

C
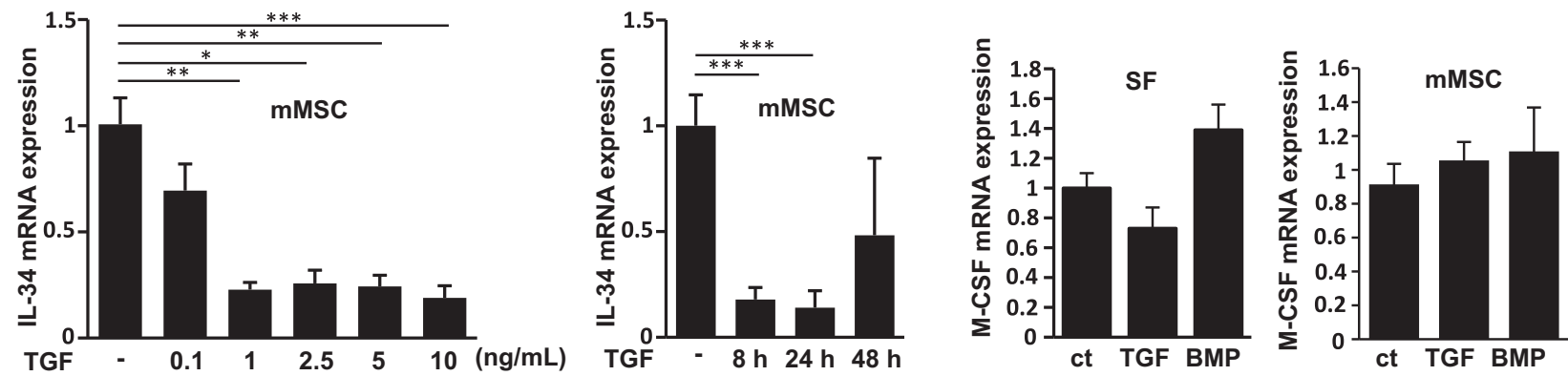

Figure 2 BMP-2 and TGF- $\beta 1$ repress IL-34 mRNA expression. A: SFs from RA patients (left panel) and mMSCs (right panel) were incubated in the presence or absence of BMP-2 $(100 \mathrm{ng} / \mathrm{mL})$ or TGF- $\beta 1(10 \mathrm{ng} / \mathrm{mL})$ for 8 hours. IL-34 mRNA levels were determined by RT-qPCR. B: mMSCs (means \pm SD) were stimulated with BMP-2 $(0,25,50,75,100$, or $200 \mathrm{ng} / \mathrm{mL})$ for 8 hours (left panel) or with $100 \mathrm{ng} / \mathrm{mL} \mathrm{BMP-2}$ for either 8, 24, or 48 hours (right panel). IL-34 mRNA levels were determined by RT-qPCR. C: mMSCs were stimulated with TGF- $\beta 1(0,0.1,1,2.5,5$, or $10 \mathrm{ng} / \mathrm{mL}$ ) for 8 hours (left panel) or with $10 \mathrm{ng} / \mathrm{mL}$ TGF- $\beta 1 \mathrm{for}$ either 8, 24, or 48 hours (right panel). IL-34 mRNA levels were determined by RT-qPCR. D: SFs or mMSCs were stimulated with BMP-2 (100 ng/mL) or TGF- $\beta 1$ $(10 \mathrm{ng} / \mathrm{mL})$ for 8 hours. M-CSF mRNA levels were determined by RT-qPCR. Data are expressed as means \pm SD. $n=7$ RA patients $(\mathbf{A}) ; n=3 \mathrm{mMSCs}(\mathbf{A}-\mathbf{D})$; $n=4$ SFs (D). ${ }^{*} P<0.05,{ }^{*} P<<0.01$, and ${ }^{* *} P<0.001$. BMP, bone morphogenetic protein; ct, control; M-CSF, macrophage colony-stimulating factor; mMSC, murine mesenchymal stem cell; RT-qPCR, real-time quantitative RT-PCR; RA, rheumatoid arthritis; SF, synovial fibroblast; TGF, transforming growth factor.

RNA was used for first-strand cDNA synthesis using ThermoScript RT-PCR System (Invitrogen). DNase I treatment (25 units, 15 minutes) of total RNA was performed to eliminate genomic contamination. Real-time PCR was performed with a Chromo4 instrument (Bio-Rad, Hercules, CA) using SYBR Green Supermix reagents (BioRad). Primer sequences were described in Table 2.

\section{Western Blot Analysis}

Western Blot analyses were performed as previously described. ${ }^{4}$ Briefly, cells were lysed in a lysis buffer (SDS $1 \%$, Tris $\mathrm{pH} 7.4,10 \mathrm{mmol} / \mathrm{L}$, sodium orthovanadate $1 \mathrm{mmol} /$ L), and protein concentration was determined by bicinchoninic acid kit (Sigma-Aldrich). Twenty micrograms of total protein in Laemmli buffer $(62.5 \mathrm{mmol} / \mathrm{L}$ Tris- $\mathrm{HCl}, \mathrm{pH} 6.8$, $2 \%$ SDS, $10 \%$ glycerol, 5\% 2-mercaptoethanol, $0.001 \%$ bromophenol blue) were separated by SDS-polyacrylamide gel electrophoresis and transferred to Immobilon-P membranes (Millipore, Billerica, MA). Membranes were immunoblotted with anti-phospho-Smad3 and Smad3 (Millipore), or phospho-Smad1/5 and Smad1/5 (Cell Signaling, Carlsbad, CA) antibodies.

\section{Confocal Microcopy Experiments}

Cell cultures, treated with TNF $\alpha(10 \mathrm{ng} / \mathrm{mL})$ and TGF- $\beta 1$ $(10 \mathrm{ng} / \mathrm{mL})$ for 24 hours, were fixed and stained with the primary antibody against IL-34 (Diaclone, INSERM UMR 957) as previously described. ${ }^{12}$

\section{Statistical Analysis}

The Spearman test was use to look for a correlation between IL-34 expression and the diagnosis. Kruskal-Wallis test was used to assess the change in gene expression. An $\alpha$ level of 0.05 was chosen to assess statistical significance.

\section{Results}

Increased Production of IL-34 and TGF- $\beta 1$ in RA Synovial Fluids

The expression of IL-34, TGF- $\beta 1$, and BMP- 2 was detected in synovial fluids of RA patients $(n=44)$ (Figure 1A). IL-34 and TGF- $\beta 1$ levels were associated with the inflammation intensity measured by the leukocyte counts $(r=0.4$, $P=0.01$ and $r=0.36, P=0.02$, respectively) 


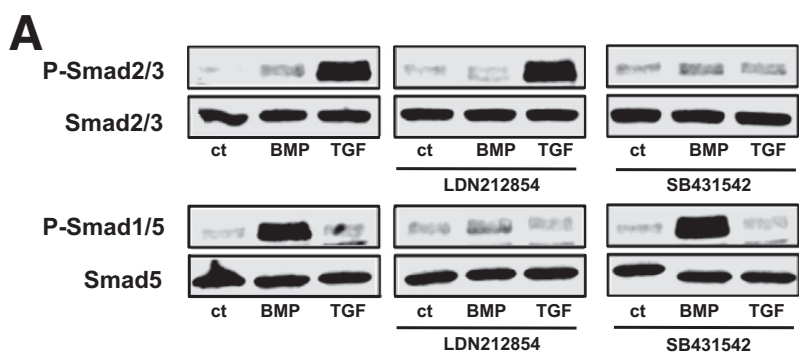

B

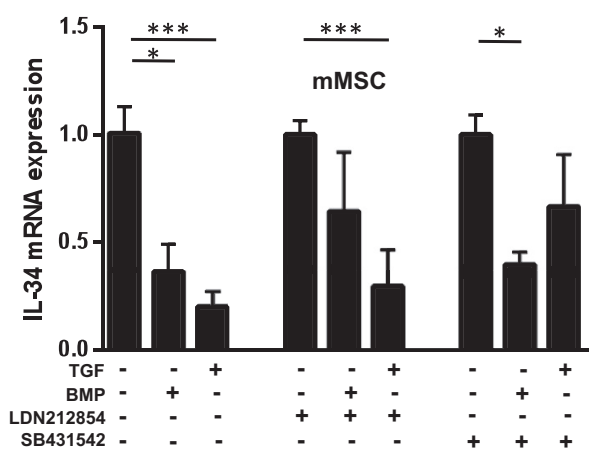

C

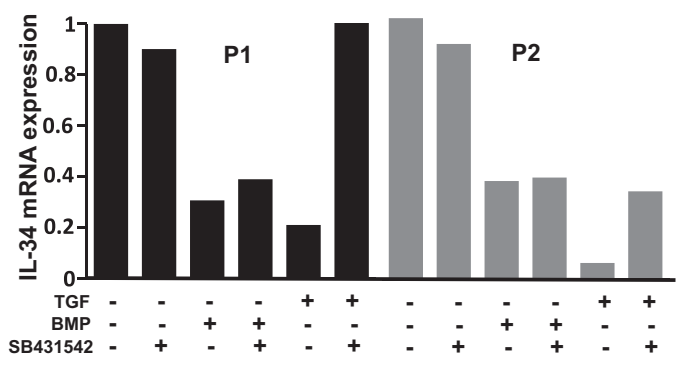

D

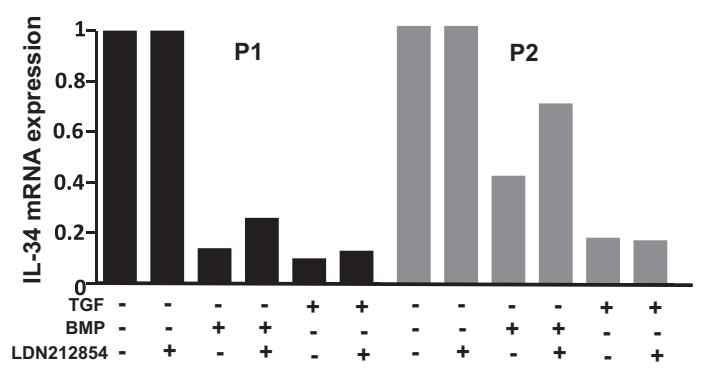

Figure 3 ALK5 and ALK1 receptors are involved in the inhibition of IL-34 expression driven by TGF- $\beta 1$ or BMP-2. A: mMSCs were incubated with SB431542 $(10 \mu \mathrm{mol} / \mathrm{L})$ or LDN212854 (10 nmol/L). One hour later, BMP-2 $(100 \mathrm{ng} / \mathrm{mL})$ or TGF- $\beta 1(10 \mathrm{ng} / \mathrm{mL})$ was added for 1 hour. Phospho-Smad levels and Smad were detected by Western blot analysis. B: mMSCs were incubated with SB431542 $(10 \mu \mathrm{mol} / \mathrm{L})$ or LDN212854 (10 nmol/L). One hour later, BMP-2 $(100 \mathrm{ng} / \mathrm{mL})$ or TGF$\beta 1(10 \mathrm{ng} / \mathrm{mL})$ was added for 8 hours. IL-34 mRNA levels were determined by RT-qPCR. C and D: Synovial fibroblasts from two patients (P1 and P2) were incubated with SB431542 $(10 \mu \mathrm{mol} / \mathrm{L} ; \mathrm{C})$ or LDN212854 (10 nmol/L; D). One hour later, BMP-2 $(100 \mathrm{ng} / \mathrm{mL})$ or TGF- $\beta 1(10 \mathrm{ng} / \mathrm{mL})$ was added for 8 hours. IL-34 mRNA levels were determined by RT-qPCR. Data are expressed as means \pm SD (B). $n=3$ (B). ${ }^{*} P<0.05,{ }^{* * *} P<0.001$. ALK1, activin receptor-like kinase 1 ; ALK5, activin receptor-like kinase 5; BMP, bone morphogenetic protein; ct, control; mMSC, murine mesenchymal stem cell; P-Smad, Phospho-Smad; RT-qPCR, real-time quantitative RT-PCR; TGF, transforming growth factor.
(Figure 1B). A positive correlation between IL-34 and TGF$\beta$ levels in synovial fluids was found $(r=0.63$, $P<0.0001$ ) (Figure 1C). No significant association was found between BMP-2 and IL-34 expression (Figure 1C) and between BMP-2 and the inflammation intensity measured by the leukocyte counts (Figure 1B).

\section{TGF- $\beta 1$ and BMP-2 Decrease IL-34 Expression in Human RA Synovial Fibroblasts and Murine MSCs}

The IL-34 mRNA steady state levels after TGF- $\beta 1$ or BMP2 treatment were next investigated by quantitative RT-PCR. Both TGF- $\beta 1(10 \mathrm{ng} / \mathrm{mL})$ and BMP-2 (100 ng/mL) significantly decreased IL-34 mRNA steady state levels in synovial fibroblasts from seven different RA patients (Figure 2A) and in other mesenchymal cells such as mMSCs (Figure 2A). The decrease of IL-34 expression in the presence of TGF- $\beta 1$ or BMP- 2 resulted in a time- and dosedependent inhibition of IL-34 mRNA (Figure 2, B and C). In contrast, neither TGF- $\beta 1$ nor BMP-2 down-regulated macrophage colony-stimulating factor in human synovial fibroblasts or in mMSCs (Figure 2D).

\section{ALK5 and ALK1 Receptors Are Involved in the Inhibition of IL-34 Expression Driven by TGF- $\beta 1$ or BMP-2}

Because BMP- 2 and TGF- $\beta 1$ preferentially signal from the membrane to the nucleus via ALK1 and ALK5 receptors, respectively, we used validated chemical inhibitors of ALK1 (LDN 212854) and ALK5 (SB431542). We first demonstrated that BMP- 2 and TGF- $\beta 1$ stimulate the ALK1/ Smad1-5 and the ALK5/Smad2-3 signaling pathways, respectively (Figure 3A). Second, we demonstrated that LDN 212854 and SB431542 specifically inhibit the ALK1/ Smad1-5 and the ALK5/Smad2-3 signaling pathways (Figure 3A). Then we observed that ALK1 and ALK5 inhibitors block the response to BMP-2 and TGF- $\beta 1$ in mMSCs, respectively (Figure 3B). Similarly, in fibroblasts of two RA patients (P1 and P2), we observed that the ALK5 inhibitor reverses the effect of TGF- $\beta 1$ on IL-34 gene expression and that the ALK1 inhibitor partially reverses the effect of BMP-2 (Figure 3, C and D). Interestingly, TGF- $\beta 1$ stimulates BMP-2 mRNA steady state level in RA synovial fibroblasts (Supplemental Figure S1).

\section{TGF- $\beta 1$ and BMP-2 Inhibit IL-34 Expression in Inflammatory Conditions}

Because proinflammatory cytokines such as IL-1 $\beta$ and $\mathrm{TNF} \alpha$ play a crucial role in RA and because we previously demonstrated that TNF $\alpha$ induces IL-34 expression, ${ }^{5}$ we studied the effect of TGF- $\beta 1$ and BMP-2 in inflammatory conditions. To this end, cells were treated with TNF $\alpha$. As shown in Figure 4A, TGF- $\beta 1$ and BMP-2 significantly reduce the IL-34 expression in the presence 


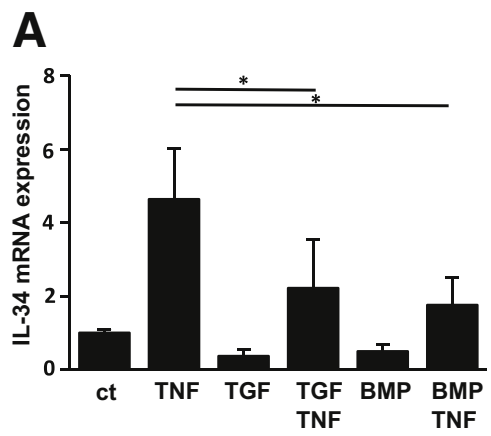

B
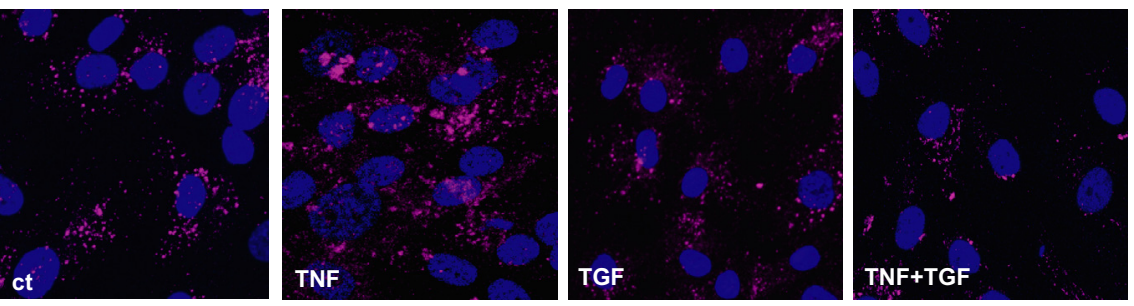

Figure 4 TGF- $\beta 1$ antagonizes TNF $\alpha$-induced IL-34. A: Synovial fibroblasts from RA patients were stimulated with TNF $\alpha$ (10 ng/mL) together with TGF- $\beta 1$ $(10 \mathrm{ng} / \mathrm{mL})$ or BMP-2 $(100 \mathrm{ng} / \mathrm{mL})$ for 8 hours. IL-34 mRNA levels were determined by RT-qPCR. B: Synovial fibroblasts cultured on Labtek chamber slides were treated with TNF $\alpha(10 \mathrm{ng} / \mathrm{mL})$, TGF- $\beta 1(10 \mathrm{ng} / \mathrm{mL})$, or both for 24 hours. IL-34 expression (pink) and nuclei stained by Hoechst reagent (blue) were observed by confocal microscopy. A representative experiment is shown. Data are expressed as means \pm SD (A). $n=7$ RA patients $(\mathbf{A})$. ${ }^{*} P<0.05$. Original magnification, $\times 40$ (B). BMP, bone morphogenetic protein; ct, control; RA, rheumatoid arthritis; RT-qPCR, real-time quantitative RT-PCR; TGF, transforming growth factor; TNF $\alpha$, tumor necrosis factor $\alpha$.

of TNF $\alpha$. Specifically, TGF- $\beta 1$ and BMP-2 repress the basal level of IL-34 rather than directly the response of the cells to TNF $\alpha$. Confocal microscopy analyses confirmed that the induction of IL-34 production induced by $\mathrm{TNF} \alpha$ is blocked in the presence of TGF- $\beta 1$ (Figure 4B). Note that the low level of IL-34 production detected in the control condition (without TNF $\alpha$ ) did not allow us to observe the decrease of the IL-34 production in response to TGF- $\beta 1$.

\section{Discussion}

Scientific studies have focused on the complex role of cytokines in the development and progression of RA. During the past decade, it has been demonstrated that proinflammatory cytokines such as TNF $\alpha$ or IL-1 $\beta$ play a crucial role in the pathophysiology of RA. These cytokines indeed promote inflammation and osteoclastogenesis in the arthritic joint, leading to the destruction of cartilage and bone. ${ }^{13}$ In this context, neutralizing $\mathrm{TNF} \alpha$ has proven successful to control RA in many cases. ${ }^{13}$ During the past years, new proinflammatory cytokines, such as IL-32, IL34 , or IL-35, have been studied for their role in the pathogenesis of RA. We demonstrated that IL-34, as a downstream effector of TNF $\alpha$ and IL- $1 \beta$, is involved in the pathogenesis of RA. ${ }^{5}$

A better understanding of the mechanisms regulating the expression of this cytokine should allow the development of new therapeutic approaches. We identified here two cytokines, BMP- 2 and TGF- $\beta 1$, able to inhibit IL-34 gene expression. We specifically demonstrated that TGF-

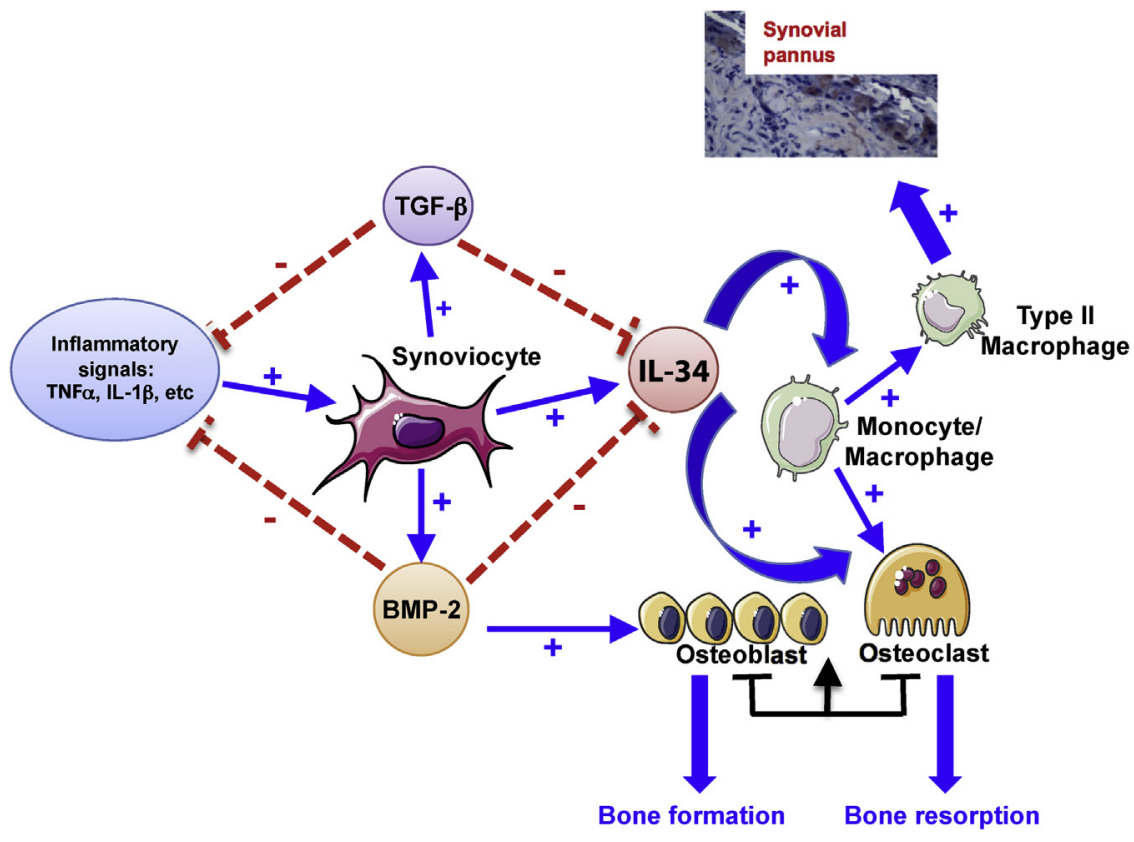

Figure 5 Schematic representation of the regulation of IL-34 expression in RA. IL-34, a cytokine produced by synovial fibroblasts in response to proinflammatory cytokines such as IL-1 $\beta$ and TNF $\alpha$, is able to stimulate type II macrophage differentiation, leading to synovial pannus proliferation, osteoclastogenesis, and, thus, bone resorption. TGF- $\beta 1$ and BMP- 2 also secreted by synovial fibroblasts decrease IL-34 secretion and function. BMP, bone morphogenetic protein; RA, rheumatoid arthritis; TGF, transforming growth factor; TNF $\alpha$, tumor necrosis factor $\alpha$. 
$\beta 1$ and BMP-2 inhibit IL-34 expression in synovial fibroblasts and in mMSCs via the ALK1 and ALK5 receptors, respectively. BMP-2 may indirectly reduce bone resorption by inhibiting the expression of IL-34 known to be able to stimulate osteoclastogenesis. ${ }^{4}$ BMP-2 could thus prevent the bone degradation in RA by directly stimulating bone formation and indirectly by inhibiting bone resorption.

The role of TGF- $\beta$, identified as a profibrotic agent in many tissues, ${ }^{14}$ remains unclear in RA. It appears that this cytokine, involved in the pannus development, ${ }^{9}$ could act as a profibrotic agent in RA. In this context, some researchers demonstrated the beneficial effects of TGF- $\beta$ in RA. ${ }^{6}$ Indeed, systemic administration of TGF- $\beta 1$ antagonized the development of polyarthritis in susceptible rats. ${ }^{15}$ In addition, the inhibition of TGF- $\beta$ signaling increased the clinical severity of arthritis in collagen-induced arthritis model. ${ }^{10}$ Here, we demonstrated that TGF- $\beta$ is able to repress IL-34 expression; therefore, it could reduce the ability of IL-34 to stimulate osteoclastogenesis. In contrast, it has been demonstrated that TGF- $\beta$ is able to stimulate the expression of receptor activator of nuclear factor $-\kappa \mathrm{B}$ ligand known to induce osteoclastogenesis. ${ }^{16}$ This discordance could explain in part the controversial effects of TGF- $\beta$ in RA and that homeostatic pathways, including TGF- $\beta$, fail to resolve synovitis.

In summary, we describe the regulation of IL-34 expression by BMP- 2 and TGF- $\beta$ in the context of inflammatory stimulation. Such control loops appear to play a key role in the control of inflammation and bone resorption in RA (Figure 5). Although it seems difficult to directly target these cytokines (BMP-2 and TGF-1) which have pleiotropic effects in different cells types, a better understanding of the regulation of IL-34 expression should allow researchers to define new targets against IL-34 in RA.

\section{Supplemental Data}

Supplemental material for this article can be found at http://dx.doi.org/10.1016/j.ajpath.2016.09.015.

\section{References}

1. Klareskog L, Catrina AI, Paget S: Rheumatoid arthritis. Lancet 2009, 373:659-672

2. Bartok B, Firestein GS: Fibroblast-like synoviocytes: key effector cells in rheumatoid arthritis. Immunol Rev 2010, 233:233-255
3. Lin H, Lee E, Hestir K, Leo C, Huang M, Bosch E, Halenbeck R, Wu G, Zhou A, Behrens D, Hollenbaugh D, Linnemann T, Qin M, Wong J, Chu K, Doberstein SK, Williams LT: Discovery of a cytokine and its receptor by functional screening of the extracellular proteome. Science 2008, 320:807-811

4. Baud'huin M, Renault R, Charrier C, Riet A, Moreau A, Brion R, Gouin F, Duplomb L, Heymann D: Interleukin-34 is expressed by giant cell tumours of bone and plays a key role in RANKL-induced osteoclastogenesis. J Pathol 2010, 221:77-86

5. Chemel M, Le Goff B, Brion R, Cozic C, Berreur M, Amiaud J, Bougras G, Touchais S, Blanchard F, Heymann MF, Berthelot JM, Verrecchia F, Heymann D: Interleukin 34 expression is associated with synovitis severity in rheumatoid arthritis patients. Ann Rheum Dis 2012, 71:150-154

6. Pohlers D, Brenmoehl J, Löffler I, Müller CK, Leipner C, Schultze-Mosgau S, Stallmach A, Kinne RW, Wolf G: TGF-[beta] and fibrosis in different organs - molecular pathway imprints. Biochim Biophys Acta 2009, 1792:746-756

7. Pohlers D, Beyer A, Koczan D, Wilhelm T, Thiesen HJ, Kinne RW: Constitutive upregulation of the transforming growth factor-beta pathway in rheumatoid arthritis synovial fibroblasts. Arthritis Res Ther 2007, 9:R59

8. Cho ML, Min SY, Chang SH: Transforming growth factor beta1 (TGF-beta1) down-regulates TNFalpha-induced RANTES production in rheumatoid synovial fibroblasts through NF-kappaBmediated transcriptional repression. Immunol Lett 2006, 105: $159-166$

9. Müssener A, Funa K, Kleinau S, Klareskog L: Dynamic expression of transforming growth factor-betas (TGF-beta) and their type I and type II receptors in the synovial tissue of arthritic rats. Clin Exp Immunol 1997, 107:112-119

10. Schramm C, Kriegsmann J, Protschka M, Huber S, Hansen T, Schmitt E, Galle PR, Blessing M: Susceptibility to collagen-induced arthritis is modulated by TGFbeta responsiveness of T cells. Arthritis Res Ther 2004, 6:R114-R119

11. Lories RJ, Luyten FP: Bone morphogenetic protein signaling in joint homeostasis and disease. Cytokine Growth Factor Rev 2005, 16 : 287-298

12. Segaliny AI, Mohamadi A, Dizier B, Lokajczyk A, Brion R, Lanel R, Amiaud J, Charrier C, Boisson-Vidal C, Heymann D: Interleukin-34 promotes tumor progression and metastatic process in osteosarcoma through induction of angiogenesis and macrophage recruitment. Int $\mathrm{J}$ Cancer 2005, 137:73-85

13. Venkatesha SH, Dudics S, Acharya B, Moudgil KD: Cytokinemodulating strategies and newer cytokine targets for arthritis therapy. Int J Mol Sci 2014, 16:887-906

14. Verrecchia F, Mauviel A, Farge D: Transforming growth factor-beta signaling through the Smad proteins: role in systemic sclerosis. Autoimmun Rev 2006, 5:563-569

15. Brandes ME, Allen JB, Ogawa Y, Wahl SM: Transforming growth factor beta 1 suppresses acute and chronic arthritis in experimental animals. J Clin Invest 1991, 87:1108-1113

16. Omata $\mathrm{Y}$, Nakamura $\mathrm{S}$, Koyama $\mathrm{T}$, Yasui $\mathrm{T}$, Hirose J, Izawa $\mathrm{N}$, Matsumoto T, Imai Y, Seo S, Kurokawa M, Tsutsumi S, Kadono Y, Morimoto C, Aburatani H, Miyamoto T, Tanaka S: Identification of Nedd9 as a TGF-[beta]-Smad2/3 target gene involved in RANKL-induced osteoclastogenesis by comprehensive analysis. PLoS One 2016, 11:e0157992 